\title{
CLINICAL CHARACTERISTICS IN PATIENTS WITH TYPE 2 DIABETES MELLITUS: A COHORT STUDY
}

\author{
Herranz Antolín S, Álvarez de Frutos V, Platero Rodrigo E, Sutil Folgado A, Mateo Pascual D. \\ Department of Endocrinology. Hospital Universitario de Guadalajara. Guadalajara. Spain.
}

\section{OBJETIVES}

Type 2 diabetes mellitus (T2DM) is a chronic disease that has increased both its prevalence and incidence in the last 50 years and is an independent risk factor for macrovascular and microvascular disease. The aim of the study is to analyze the grade of metabolic control, cardiovascular risk factors and treatments in T2DM cohort of patients.

\section{METHODS}

Observational, cross-sectional and prospective study of 238 T2DM patients who consult in endocrinology clinics for the first time or those who did not undergo periodic revisions during the previous year of the study. All reported patients were outpatients, over 18 years of age and they signed informed consent. Patients with other types of diabetes or inpatients were excluded. Period of the study: from November 2013 to January 2014. We measured the goals of control in diabetic patients, the prevalence of chronic complications and the used treatment. Statistical analysis was done by SPSS 20.0 .

\section{RESULTS}

The study was composed by $61.8 \%$ men and $38.2 \%$ woman with a mean age of $64.2 \pm 12.7$ years.

Diabetes duration: < 1 year $8.8 \%$; $1-5$ years $20.2 \%$; $5-10$ years $25.2 \%$; > 10 years $45.8 \%$.

Cardiovascular risk factors: hypertension $80.7 \%$, dyslipidemia $80.3 \%$, smoking $18.9 \%$ and obesity $61.4 \%$ (body mass index $33.4 \pm 8.2 \mathrm{~kg} / \mathrm{m}^{2}$ ); waist perimeter $109.6 \pm 16.2 \mathrm{~cm}$.

$\mathrm{HbA1c}$, lipids, blood pressure level and degree of control are shown in table 1. Neither of patients achieved all of targets. Hypoglycaemic agent are shown in graphic 1.

Antihypertensive drugs $74.8 \%$; lipid lowering drugs $64.3 \%$; antiplatelet agents $41.1 \%$.

No ocular fundus examination (12 months previous): $65.1 \%$. Normal $24.4 \%$; mild diabetic retinophathy (DR) $3.4 \%$; moderate DR $3.4 \%$; severe DR $0.8 \%$; proliferative DR $4.6 \%$; macular edema $3.8 \%$.

Microalbumin-to-creatinine ratio test (6 months previous) $50.4 \%$ (normal $29.4 \%$; microalbuminuria $16.4 \%$; macroalbuminuria $4.6 \%$ ). The prevalence of cerebral, peripheral and coronary vascular disease was $5.9 \%, 10.1 \%$ and $18.5 \%$ respectively. The prevalence of amputation was $2.9 \%$ and diabetic food $5.1 \%$.

Table 1. HbA1c, lipids, blood pressure level, and degree of control

\begin{tabular}{llll} 
& Mean $\pm \mathrm{sd}$ & $\begin{array}{l}\text { Targets (ADA 2013- } \\
2014)\end{array}$ & $\begin{array}{l}\text { \% patients } \\
\text { achieved targets }\end{array}$ \\
\hline HbA1c $(\%)$ & $8.1 \pm 1.9$ & $\leq 7$ & 37.3 \\
\hline $\begin{array}{l}\text { LDL-c }(\mathrm{mg} / \mathrm{dl}) \\
\text { HDL-c }(\mathrm{mg} / \mathrm{dl})\end{array}$ & $109.6 \pm 43.0$ & $\leq 100$ & 44.8 \\
\hline $\begin{array}{l}\text { Triglycerides } \\
\text { (mg/dl) }\end{array}$ & $169.3 \pm 10.9$ & $\geq 50$ & 21.7 \\
$\begin{array}{l}\text { Systolic BP } \\
\text { (mmHg) }\end{array}$ & $140.1 \pm 21.6$ & $\leq 150$ & 53.4 \\
$\begin{array}{l}\text { Dyastolic BP } \\
\text { (mmHg) }\end{array}$ & $77.4 \pm 12.7$ & $\leq 80$ & 36.3 \\
\hline
\end{tabular}

$30.3 \%$ and $24.7 \%$ of patients have not $\mathrm{HbA} 1 \mathrm{c}$ and lipids tests respectively during the 6 months preceding the study.
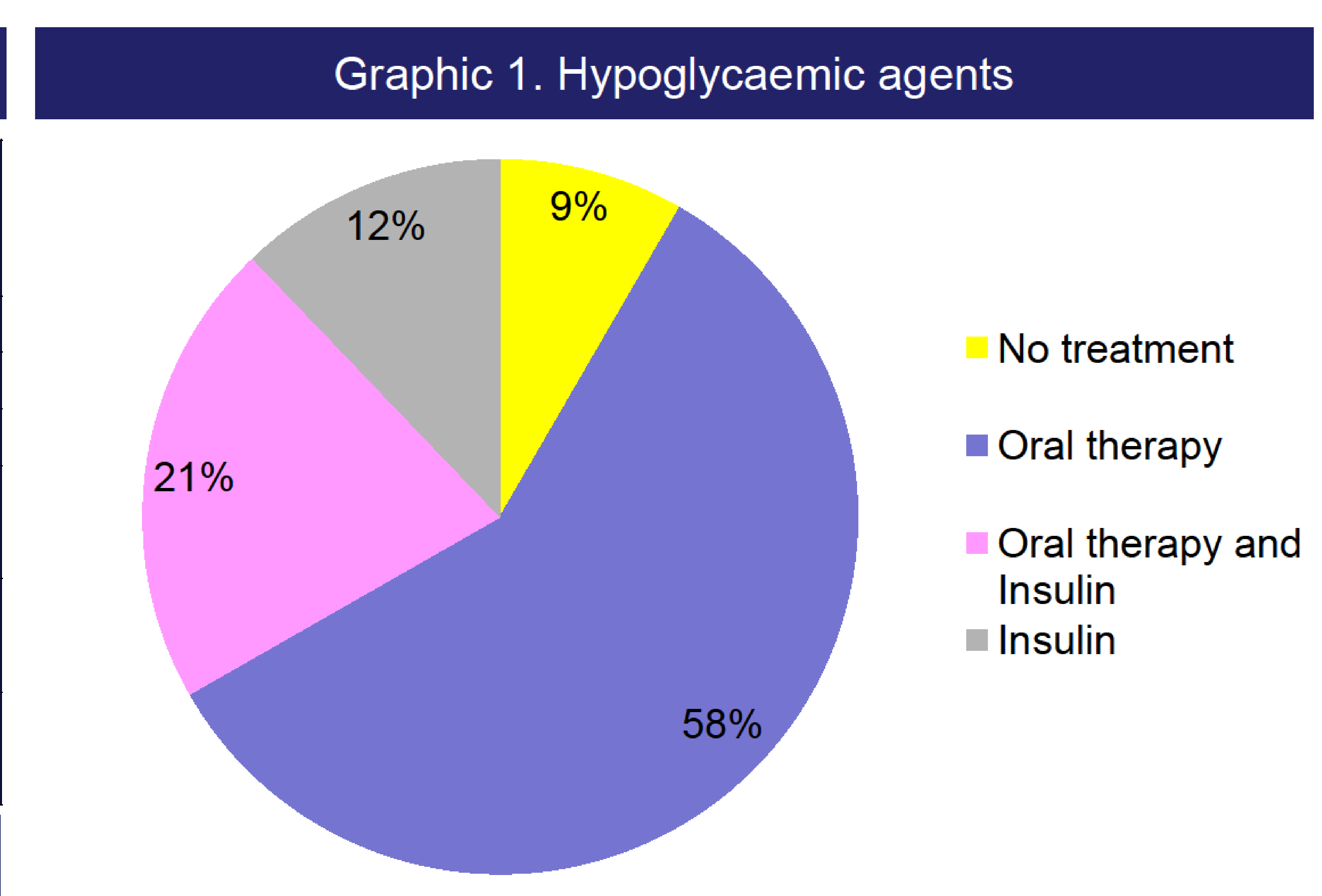

\section{CONCLUSIONS}

- The prevalence of cardiovascular risk factors was very high in our study. However, neither patients achieved all ADA targets, in spite of the wide use of antihypertensive, lipid lowering and hypoglycaemic drugs.

- The screening of complications was not optimal in our study. 